\title{
POU Domain, Class 5, Transcription Factor 1 Staining Method
}

National Cancer Institute

\section{Source}

National Cancer Institute. POU Domain, Class 5, Transcription Factor 1 Staining Method. NCl Thesaurus. Code C122841.

An immunohistochemical technique used to detect the presence of POU domain, class 5, transcription factor 1 in a tissue sample. 